American Journal of Pharmaceutical Education 2018; 82 (10) Article 7192.

\title{
COMMENTARY
}

\section{Empathy and the Development of Affective Skills}

\author{
Anna Ratka, PharmD, $\mathrm{PhD}^{\mathrm{a}, \mathrm{b}}$ \\ ${ }^{a}$ Wegmans School of Pharmacy, St. John Fisher College, Rochester, New York \\ ${ }^{\mathrm{b}}$ Editorial Board Member, American Journal of Pharmaceutical Education, Arlington, Virginia
}

Submitted June 3, 2018; accepted October 5, 2018; published December 2018.

\begin{abstract}
Empathy, the most important human attribute that matters in every aspect of life, is essential in health care. Provision of patient-centered care requires empathic health care practitioners. The correlation between empathy of health care providers and improved patient adherence, satisfaction, and treatment outcomes is well-established. Scholarly evidence shows positive correlations between empathy and affective domains and confirms that soft skills are grounded in empathy. Empathic students have stronger affective skills and are capable to acquire, develop, reinforce, and display strong affective behaviors, abilities, and attitudes. As an innate quality, empathy is malleable. The level of empathy can be influenced by educational interventions inculcated into students during the entire curriculum, including both didactic and experiential training. The effectiveness of educational methods may be strengthened by activities that help students enhance empathy and achieve required affective skills. Empathy and the empathy-based affective skills essential in patient-centered care should be routinely and deliberately taught, modelled, and assessed across the continuum of health care curricula.
\end{abstract}

Keywords: empathy, affective skills, educational interventions, students

\section{Empathy as a Human Attribute}

Roughly defined, empathy is the ability to put yourself in somebody else's shoes, or to "feel their pain." Empathy as a human attribute matters in many aspects of life. As a multidimensional phenomenon, empathy incorporates affective, cognitive, behavioral, and moral components. Researchers identified two types of empathy: affective and cognitive. Affective empathy are sensations and feelings in response to another person's emotions. Cognitive empathy refers to the ability to identify and understand emotions of others. Empathic people can identify and understand situations, feelings, motives, and perspectives, and, moreover, recognize and appreciate concerns of another person; they cultivate curiosity about strangers, challenge prejudice and discover commonalities, try another person's life, listen, open up, inspire mass action and social change, and develop an ambitious imagination. ${ }^{1}$

Neuroscience discoveries demonstrate that the human brain is hardwired for empathy. The different levels of empathy related to thoughts, feelings, and actions are supported by different brain networks. ${ }^{2}$ There is also a genetic basis for empathy. ${ }^{3}$ Growing evidence supports individual variability in empathy; mature individuals and females have higher empathy scores. ${ }^{4}$ Cultural differences in empathic responses

Corresponding Author: Anna Ratka, Wegmans School of Pharmacy, St. John Fisher College, Rochester, NY. Tel: 585899-3807. E-mail: aratka@sjfc.edu to physical and social stimuli at both cognitive and affective level were reported. ${ }^{5}$ Empathy can decline or be enhanced during the lifespan. Meta-analysis of empathy data collected between 1979 and 2009 showed a 40\% decline in empathy level among college students. ${ }^{6}$

\section{Empathy in Patient Care}

Empathy is essential in the provision of patientcentered care and is described as the ability to understand the patient's situation, perspectives, and feelings; communicate that understanding and check its accuracy; and, then act on that understanding with the patient. ${ }^{7}$ These three action words, understand, communicate, and act, are the foundation for effective and high quality therapeutic relationship with the patient. In relevance to a clinical setting, empathy is multidimensional and includes emotional, moral, cognitive, and behavioral aspects. ${ }^{8}$ All dimensions of clinical empathy should be used together to work effectively. The correlation between empathy of health care providers and improved patient adherence, satisfaction, and treatment outcomes is well-established. Moreover, professional satisfaction of health care providers is also correlated with empathy. ${ }^{8}$

\section{Empathy and Affective Skills}

Effective delivery of compassionate and collaborative patient-centered care requires empathy-based skills and should be routinely and deliberately taught, modelled, and assessed across the continuum of health care 


\section{American Journal of Pharmaceutical Education 2018; 82 (10) Article 7192.}

curricula. Competencies in affective skills are included in accreditation standards as required curricular outcomes. The Association of American Medical Colleges included empathy as an essential learning objective for medical education. ${ }^{9}$ The American Association of Colleges of Nursing emphasize the importance of empathy in nursing education. ${ }^{10}$ Empathy is a requirement in Competency 6 in accreditation standards for the master's degree in social work. ${ }^{11}$ The 2016 Standards of the Accreditation Council for Pharmacy Education define accreditation requirements for affective skills; affective skills for personal and professional development (Standard 4) translate to skills needed in approach to practice and care (Standard 3). ${ }^{12}$ Affective competencies essential for student pharmacists include problem solving, education, advocacy, interprofessional collaboration, cultural sensitivity, communications, self-awareness, leadership, innovation and entrepreneurship, and professionalism. ${ }^{12}$

To represent patients' interest, health care practitioners should be able to advocate for their patients. Curriculum based on empathy resulted in improved advocacy. ${ }^{13}$ Empathy was shown to play a positive role in the development of inteprofessional collaborative practice and attitudes toward interprofessional collaboration. ${ }^{14}$ Interpersonal communications were enhanced by empathy; empathic professionals communicate ${ }^{15}$ and listen ${ }^{16}$ more reflectively. Empathy was shown to have a positive impact on the ability to recognize social determinants and disparities in health care ${ }^{17}$ and reduce prejudice. $^{18}$

Poor cognitive empathy was correlated with deficiencies in self-awareness of emotional states. ${ }^{19}$ It is critical for an empathic health practitioner engaged in addressing a patient's needs to maintain self-awareness that this is the experience of another person. Empathy helps self-aware individuals to examine and reflect on personal knowledge, skills, abilities, beliefs, biases, motivation, and emotions.

Empathy is considered an integral part of professionalism along with knowledge, humanism, and competence. ${ }^{20}$ Professionalism based on empathy has special implications in patient-centered and collaboration-based health care. ${ }^{20}$ Leaders with empathy were shown to thoughtfully consider feelings of others, increase use of teams, excel in crosscultural communications, and demonstrate ability for creating and achieving shared goals. ${ }^{21}$ Empathic innovators and entrepreneurs were found to be reflective and able to think about the impact of a technological product on its users. ${ }^{22}$ Phrases such as "empathy marketing" or "empathy selling" are progressively being introduced along rapid technological changes in health care.

\section{Methods to Enhance Empathy}

Empathy, as an innate quality, is malleable and can be enhanced by strategic educational intereventions. ${ }^{8,23}$
Training on development of communication skills resulted in significant increase in empathy scores. ${ }^{24}$ Integration of live experience interviews significantly increased empathy toward vulnerable groups of patients. ${ }^{25}$ Empathy was promoted by use of video recordings of patients' stories, ${ }^{24}$ service to underserved communities, ${ }^{17}$ and reflective writing. ${ }^{27,28}$ To advance empathy in medical students, five approaches were effective: early clinical exposure (direct patient contact or simulated patient); playing a role of a patient; exposure to literary and performing arts; improving communication, narrative, and stress management skills; and exposure to role models. ${ }^{33}$ Role-modeling by clinical instructors during experiential training was reported as the most important influence on empathy education. ${ }^{34}$ Significant improvement in empathy resulted from exposure to a 3D simulation of culturally and linguistically diverse patients in a hospital setting ${ }^{31}$ and simulations of medical consultations with standardized patients. ${ }^{30,32}$ Other educational strategies used to enhance empathy included: writing, problem-based learning, patient interviews, interprofessional education, experiential training. These strategies were showed to be effective in maintaining and enhancing empathy. ${ }^{8,29}$

Programs targeted to enhance empathy need reinforcements for a sustained effect. The strategies that were suggested to sustain and promote empathy include reinforcement of communication skills and relocation of clinical training from hospitals to chronic care, home care, hospice, and long-term care settings. ${ }^{24,35}$

Literature reports described above demonstrate that empathy can be improved with many different teaching strategies. The multidimensional nature of empathy makes assessment of effectiveness of empathy-enhancing strategies complicated. Ideally, empathy assessment tools should measure: meaning of empathy, willingness to empathize, individual empathic ability, barriers to express empathy, change in empathy level, empathy education, and empathic abilities. Several validated tools are available to measure empathy. ${ }^{8,36}$ Regular assessment of empathy can help to monitor progress in development and/or changes of affective competencies.

\section{Empathy, the Catalyst}

The positive correlation between empathy and affective skills suggests that in absence of empathy, students may not be able to effectively acquire, develop, and display affective behaviors, abilities, and attitudes. Empathy plays a role of a catalyst for the process of affective skills development. The catalytic properties of empathy enable and facilitate reaction resulting in affective domains products. Empathy-catalyzed formation of affective skills is essential to students' personal and professional development and readiness for empathic patient-centered care. 


\section{American Journal of Pharmaceutical Education 2018; 82 (10) Article 7192.}

\section{CONCLUSION}

Empathy helps students develop affective skills, behaviors, and attitudes, achieve competencies essential for patient-centered care, and advance personal and professional development. As an innate human attribute, empathy shows inter-individual variability and can change over time. Educators in health professional programs should recognize that many affective skills are rooted in empathy. Empathy is malleable, and empathy can enable, catalyze, and facilitate achievement of affective skills, attitudes, and behaviors.

Literature reports describe positive correlation between empathy and affective skills and provide examples of educational interventions to enhance empathy. Health professional programs should implement educational strategies that develop, reinforce, nourish, and sustain empathy in students. Due to its contextual and multidimensional nature, empathy development needs to be inculcated throughout the curriculum, both didactic and experiential.

Academic pharmacy and other health care programs are entrusted with an important task to educate and develop competent value-centered health care professionals with a high level of empathy and strong affective abilities that are essential for adequate patient-centered and team-based health care. Theodore Roosevelt said, "Nobody cares how much you know, until they know how much you care."

\section{REFERENCES}

1. Krznaric R. Six habits of highly empathic people.

2012 https://greatergood.berkeley.edu/article/item/six_habits_of_ highly_empathic_people1. Accessed April 2, 2018.

2. Engen HG, Singer T. Empathy circuits. Curr Opin Neurobiol. 2013;23(2):275-282.

3. Warrier V, Toro R, Chakrabarti B, et al. Genome-wide analyses of self-reported empathy: correlations with autism, schizophrenia, and anorexia nervosa. Transl Psychiat, 2018;8(1):35-45.

4. Fields SK, Mahan P, Tillman P, Harris J, Maxwell K, Hojat M. Measuring empathy in healthcare profession students using the Jefferson scale of physician empathy: health provider-student version. J Interprof Care. 2011;25(4):287-293.

5. Atkins D, Uskul AK, Cooper NR. Culture shapes empathic responses to physical and social pain. Emotion. 2016;16(5):587-601. 6. Konrath SH, Chopik WJ, Hsing CK, O'Brien E. Changes in adult attachment styles in American college students over time: a metaanalysis. Pers Soc Psychol Rev. 2014;18(4):326-348.

7. Mercer SW, Reynolds WJ. Empathy and quality of care. Br J Gen Pract. 2002;52(Suppl):S9-S12.

8. Stepien KA, Baernstein A. Educating for empathy: a review. $J$ Gen Intern Med. 2006;21(5):524-530.

9. Anderson M, Cohen J, Hadlock J, Kassebaum D, Turnbull J, Whitcomb M. Learning objectives for medical student education: guidelines for medical schools. Report I of the medical schools objectives project. Washington, DC: Association of American Medical Colleges; 1998.

10. American Association of Colleges of Nursing. The essentials of baccalaureate education for professional nursing practice. 2008.
http://aacn.nche.edu/education-resources/BaccEssentials08.pdf. Accessed April 30, 2018.

11. Council on Social Work Education. Commission on Educational Policy and the CSWE Commission on Accreditation; 2015 Educational Policy and Accreditation Standards. https://www.cswe. org/getattachment/Accreditation/Standards-and-Policies/2015EPAS/2015EPASandGlossary.pdf.aspx. Accessed April 31, 2018. 12. Accreditation Council for Pharmacy Education. Accreditation standards and key elements for the professional program in pharmacy leading to the doctor of pharmacy degree. Standards 2016. https://www.acpe-accredit.org/pdf/Standards2016FINAL. pdf. Accessed April 30, 2018.

13. Miller SR. A curriculum focused on informed empathy improves attitudes toward persons with disabilities. Perspect Med Educ. 2013; 2(3):114-125.

14. Calabrese LH, Bianco JA, Mann D, Massello D, Hojat M. Correlates and changes in empathy and attitudes toward interprofessional collaboration in osteopathic medical students. $\mathrm{J} \mathrm{Am}$ Osteopath Assoc. 2013;113(2):898-907.

15. Bays AM, Engelberg RA, Back AL, et al. Interprofessional communication skills training for serious illness: evaluation of a small-group, simulated patient intervention. J Palliat Med 2014; 17(2):159-166.

16. Pollak KI, Alexander SC, Tulsky JA, et al. Physician empathy and listening: associations with patient satisfaction and autonomy. J Am Board Fam Med. 2011;24(6):665-672.

17. Fritz C, Naylor K, Watkins Y, et al. Are we missing the mark? The implementation of community based participatory education in cancer disparities curriculum development. J Racial Ethn Health Disparities. 2015;2(2):237-243.

18. Pettigrew TF, Troop LR. How does inter-group reduce prejudice? Meta-analytic tests of three mediators. Eur J Soc Psych. 2008;38:922-934.

19. William JH, Cameron IM, Braadbaart L, Waiter GD. Perceiving and expressing feelings through actions in relation to individual differences in empathic traits: the action and feelings questionnaire (AFQ). Cogn Affect Behav Neurosci. 2016;16:248-260.

20. Arnold L. Assessing professional behavior: yesterday, today, and tomorrow. Acad Med. 2002;77(6):502-515.

21. Gunther M, Evans G, Mefford L, Coe TR. The relationship between leadership styles and empathy among student nurses. Nurs Outlook. 2007;55(4):196-201.

22. Schweitzer F, Rau C, Gassmann O, van den Hende E. Technologically reflective individuals as enablers of social innovation. J Prod Innov Manage. 2015;32(6):847-860. 23. Kelm Z, Womer J, Walter JK, Feudtner C. Interventions to cultivate physician empathy: a systematic review. BMC Med Educ. 2014;14:219-230.

24. Kataoka H, Iwase $\mathrm{T}$, Ogawa $\mathrm{H}$, et al. Can communication skills training improve empathy? A six-year longitudinal study of medical students in Japan. Med Teach. 2018;22:1-6.

25. Heidke P, Howie V, Ferdous T. Use of healthcare consumer voices to increase empathy in nursing students. Nurse Educ Pract. 2918;29:30-34.

26. Sweeney K, Baker P. Promoting empathy using video-based teaching. Clin Teach. 2018;15(4):336-340.

27. Brown KM, Bright LM. Teaching caring and competence: student transformation during an older adult focused service-learning course. Nurse Educ Pract. 2017;27:29-36. 


\section{American Journal of Pharmaceutical Education 2018; 82 (10) Article 7192.}

28. Moniz T, Artnfield S, Miller K, Lingard L, Watling C, Regehr G. Considerations in the use of reflective writing for student assessment: issues of reliability and validity. Med Educ. 2015;49(9):901-908. 29. Batt-Rawden SA, Chisolm MS, Anton B, Flickinger TE. Teaching empathy to medical students: an updated, systematic review. Acad Med. 2013;88(8):1171-1177.

30. Schweller M, Costa FO, Antonio MA, Amral EM, de CarvalhoFilho MA. The impact of simulated medical consultations on the empathy levels of students at one medical school. Acad Med. 2014;89(4):632-637.

31. Everson N, Levett-Jones T, Lapkin S, et al. Measuring the impact of a 3D simulation experience on nursing students' cultural empathy using a modified version of the Kiersma-Chen empathy scale. J Clin Nurs. 2015;24(19-20):2849-2858.
32. Lor KB, Truong JT, Ip EJ, Barnett MJ. A randomized prospective study on outcomes of an empathy interventions among second-year student pharmacists. Am J Pharm Educ. 2015;79(2): Article 18.

33. Ziolkowska-Rudowicz E, Kladna A. Empathy-building of physicians. Parts I-IV. Pol Merkur Lekarski. 2010;29(172):277-286; 29(173):331-335; 29(174):400-404.

34. Tavakol S, Dennick R, Tavakol M. Medical students' understanding of empathy: a phenomenological study. Med Educ. 2012;46(3):306-316.

35. Benbassat J, Baumal R. What is empathy, and how can it be promoted during clinical clerkships? Acad Med. 2004:79(9):832-839. 36. Kiersma ME, Chen AMH, Yehle KS, Plake KS. Validation of an empathy scale in pharmacy and nursing students. Am J Pharm Educ. 2013;77(5):Article 94. 